\title{
In Reference to "Virtual Meetings are Here to Stay: A Commentary on Virtual Meetings and Conferences in COVID Times"
}

Kaushik Samanta

Bengal Physician Journal (2021): 10.5005/jp-journals-10070-7056

Sir/Madam,

This letter is in reference to "Virtual Meetings are here to stay: A Commentary on Virtual Meetings and Conferences in COVID Times." The article is very apt and well written in the current scenario of the COVID-19 pandemic. Due to this devastating COVID-19, the way of medical meetings is now on the verge of metamorphosis universally. Previously, it was a hassle to travel nationally and internationally to attend conferences, but it is very convenient due to the new advent of virtual meetings. In addition, from an environmental perspective, we have certainly reduced carbon emissions and footprint ${ }^{2}$ and depletion of the ozone layer significantly in the last year.

We have absorbed and assimilated more information without having to contend with the cognitive side effects of jet lag as before. ${ }^{3}$ COVID-19 is becoming a lousy companion of our civilization. As it is evident that the aerosol route is the most definite and critical route for transmission among people, we cannot arrange medical meetings in a hall or place. There will always be the issue of "superspreaders" and asymptomatic carriers who cannot be screened out for these meetings.

The virtual meeting format provides global access and a level playing field to all participants who are no longer restrained ${ }^{4,5}$ because of financial, family, and health concerns. The economization of time and energy is a significant gain, and it has made learning more efficient. We do not have to face jet lag or uncomfortable environments anymore.

The trainees are getting more benefits as it opens up the global networks to them in the early days of their academic careers. The anxiety of presenting in unfamiliar surroundings is no more a hindrance. Now, one can effortlessly solve their queries because of face-to-face interaction. ${ }^{6}$ It was indeed tough previously.

Now, all the sessions are readily available for post-conference viewing, and so, recapitulation and dissemination of information to colleagues and students can be done later. Another significant achievement of the virtual format is that it has crossed all the geographical boundaries and made it universally accessible even in the remote areas of Africa. ${ }^{7}$

The virtual platform is cost-effective too, and the users only have to pay for the internet, which reduces the price too as minimum as $0.5 \%$ of the previously required cost.

I am now coming to the downside of this format. Many professional bodies who had a significant share of the revenues generated from those conferences have faced a dent in their earnings. The hospitality and travel sectors and the industry partners who heavily relied on the stalls for their advertisement have also suffered losses. The transition to virtual meetings has probably also hampered professional development. The scope of
Department of Internal Medicine, RG Kar Medical College and Hospital, Kolkata, West Bengal, India

Corresponding Author: Kaushik Samanta, Department of Internal Medicine, RG Kar Medical College and Hospital, Kolkata, West Bengal, India, Phone:+91 917908231078, e-mail: kaushik.samanta555@gmail.com How to cite this article: Samanta K. In Reference to "Virtual Meetings are Here to Stay: A Commentary on Virtual Meetings and Conferences in COVID Times". Bengal Physician Journal 2021;8(2):59.

Source of support: Nil

Conflict of interest: None

personal and professional development in public speaking and critical thinking is certainly not there in the virtual platform.

In conclusion, in the present context of this deadly pandemic where a large gathering should preferably be avoided, we have to step forward to the virtual future.

\section{References}

1. Porpiglia F, Checcucci E, Autorino R, et al. Traditional and virtual congress meetings during the COVID-19 pandemic and the post-COVID-19 era: is it time to change the paradigm? Eur Urol 2020378(3):301-303. DOI: 10.1016/j.eururo.2020.04.018. PMID: 32334884; PMCID: PMC7158826.

2. Duane B, Lyne A, Faulkner T, et al. Webinars reduce the environmental footprint of pediatric cardiology conferences. Cardiol Young 2021:1-8. DOI: 10.1017/S1047951121000718. PMID: 33685550.

3. Rubinger L, Gazendam A, Ekhtiari S, et al. Maximizing virtual meetings and conferences: a review of best practices. Int Orthopaed (SICOT) 2020;44(8):1461-1466. DOI: 10.1007/s00264-020-04615-9.

4. Gurwitz KT, Aron S, Panji S, et al. Designing a course model for distance-based online bioinformatics training in Africa: the H3ABioNet experience. PLoS Comput Biol 2017;13(10):e1005715. DOI: 10.1371/journal.pcbi.1005715.

5. Fadlelmola FM, Panji $S$, Ahmed $A E$, et al. Ten simple rules for organizing a webinar series. PLoS Comput Biol 2019;15(4):e1006671. DOI: 10.1371/journal.pcbi.1006671 [Erratum in: PLoS Comput Biol 2019;15(5):e1007048]. PMID: 30933972; PMCID: PMC6443143.

6. Murdock HM, Penner JC, Le $S$, et al. Virtual morning report during COVID-19: a novel model for case-based teaching conferences. Med Educ 2020;54(9):851-852. DOI: 10.1111/medu.14226. PMID: 32403168; PMCID: PMC7273056.

7. Taubert $M$, Webber $L$, Hamilton $T$, et al. Virtual reality videos used in undergraduate palliative and oncology medical teaching: results of a pilot study. BMJ Support Palliat Care 2019;9(3):281-285. DOI: 10.1136/ bmjspcare-2018-001720. PMID: 30808627; PMCID: PMC6817702. 